\title{
Toward a Broader Conceptualization of Development: The Role of Gains and Losses across the Life Span
}

\author{
David H. Uttal and Marion Perlmutter \\ Department of Psychology, University of Michigan
}

Developmental psychologists traditionally have conceived of childhood primarily as a time of positive change, or gain, and old age primarily as a time of negative change, or loss. Life-span developmental psychologists recently have challenged these assumptions, asserting that gains and losses are ubiquitous across the life span. While generally supporting this assertion, we suggest that the relation between developmental gains and losses needs to be considered in more depth. Even life-span developmentalists seem to have assumed that gains and losses are causally related, and that the direction of causality is determined by age. In this paper, we review previous considerations of gains and losses. Then, we show that losses during early life are not necessarily responses to gains, and that gains during later life are not necessarily responses to losses. Finally we suggest criteria and methods for assessing four alternative models (unrelated phenomenon, spurious phenomenon, suppression, and compensation) relevant to the causality and directionality of the relation between developmental gains and losses, 1989 Academic Press, Inc.

This paper considers the role of gains and losses in development across the life span. Traditionally, developmentalists have conceived of agerelated change during early life primarily as gain, and of age-related change in late life primarily as loss (See Baltes, 1987; Kagen, 1980). It now appears, however, that these conceptions of the nature of age-related change may be inaccurate. For example, several studies have documented potential and actual gains in old age (See Labouvie-Vief, 1985; Perlmutter, 1988; Rybash, Hoyer, \& Roodin, 1986; Salthouse, 1984). Therefore, life-span developmentalists (e.g. Baltes, 1987) have suggested that gains and losses are ubiquitous across the life span. This paper attempts to expand this view by examining more carefully assumptions and knowledge about the relation between developmental gains and losses.

Preparation of this manuscript was supported by a Rackham Graduate School Predoctoral Fellowship to David Uttal and by a Brookdale National Fellowship to Marion Perlmutter. We thank Andy Achenbaum, Cindy Adams, Catherine Arnott, Hiroshi Azuma, Bill Bacon, Fred Bookstein, Chen Chuansheng, John Hagen, Max Lummis, Jane Perlmutter, Denise Person, David Rotenizer, Steve Sternberg, Harold Stevenson, K. Warner Schaie, and Sherry Willis for their helpful comments. Correspondence concerning this article should be addressed to Marion Perlmutter, Institute of Gerontology, $300 \mathrm{~N}$. Ingalls, University of Michigan, Ann Arbor, MI 48109-2007. 
The paper has two primary goals. The first goal is to expand application of the life-span perspective. Life-span psychologists recognize that "no strong psychology of life-span development can exist without solid research on earlier phases of life" (Baltes, 1987, p. 623). Yet, at present, life-span psychologists place a disproportionate emphasis upon adulthood at the expense of childhood (See Baltes, 1987; Hetherington \& Baltes, 1988; Skinner, 1987). This paper argues that a perspective emphasizing both gains and loss can contribute to a better understanding of development at all periods of life. We show that development of the nervous system in neonates, development of problem-solving skills in elementaryschool children, and development of expertise in adulthood can be understood best when the roles of both gains and losses are considered. Moreover, we propose that a perspective that focuses both on gains and losses is advantageous because it emphasizes the antecedents of development instead of simple age-related transitory states.

The second goal is to offer new theoretical specifications about the relations between gains and losses in development. Currently, many researchers and theorists (e.g., Baltes, 1987; Charness, 1985; Salthouse, 1984) seem to suggest that gains in old age emerge to compensate for loss, and that losses in childhood are the results of gains in higher processes (e.g. Bever, 1982; Hagen, 1967; Klahr, 1982; Stevenson, 1972; Weir, 1964). These suggestions assume that gains and losses are causally related, and that the direction of causality is determined by age. In this paper we demonstrate the plausibility of alternate interpretations of the relations between gains and losses at different periods of the life span. In addition, we suggest research that could determine possible dynamics between gains and losses in development. The paper begins with a discussion of the terms gain and loss as they apply to traditional and life-span developmental psychology, and to the present paper.

\section{CONCEPTIONS OF GAINS AND LOSSES IN DEVELOPMENTAL PSYCHOLOGY}

In this section, we consider the role of gains and losses in development in the traditional and life-span views of developmental psychology. By traditional, we mean the views that have dominated the field throughout most of the 20th century; life-span refers to the views that focus on the nature of development across the life span, which are most clearly articulated by Baltes (1987).

By gain, we mean the acquisition of new structures or functions, improvements in the effectiveness or efficiency of old structures or functions, or the new application of existing structure or function to novel tasks or domains. By loss, we mean either the removal or disappearance 
of existing structures or functions, or decrements in the effectiveness or efficiency of old structures or functions. Any particular gain does not imply "better overall," and any particular loss does not imply "worse overall." Our definitions of loss and gain are not limited to biologically based growth or decline; the acquisition of a new strategy is as much a gain as the acquisition of new synapses, and the failure to use an old strategy is as much a loss as the reduction in sensory acuity in the older years. We believe that developmental psychologists have selected a rather limited subset of the types of change that they study and measure, and that the selection of the type of change to study is influenced by the period of the life span under investigation. Specifically, in traditional developmental psychology, the primary focus for research on early life is on gains, and the primary focus for research on late life is on losses. Development in early life thus can be defined in terms of the cumulative effects of gains (See Kagen, 1980), and development in late life can be defined in terms of the cumulative effects of losses (See Birren, 1988).

Two assumptions about the nature of human change may have motivated theorists to focus on gains during early life, and on losses during late life. The first of these assumptions is that development is a continuous, unidimensional process. This assumption is similar to what Kagen (1980) called faith in connectedness: developmental events are considered to be related to and based on previous events. New structure or function is derived from previous structure or function. For example, Piaget's theory of cognitive development holds that cognitive structures associated with formal operations emerge from those associated with concrete operations. Kagen suggested that "most psychologists regard development as constituted of long chains of derivatives; a process or competence grows out of a prior one, and aspects of the former are incorporated into the later entity" (p. 34). The assumption of continuity may have its roots in the legacy of both Freudian and learning theories of development, which stress the role of past experience in understanding present behavior (Flavell, 1972; Kagen, 1980).

A second assumption of traditional developmental psychology is that there is a specific goal towards which development proceeds. In Kessen's (1984) words, "The idea of development entails the existence of an endpoint; the child moves, steadily or erratically, toward a goal. . . . The problem of goals hovers over all attempts to understand human development" (pp. 4-5). In addition, the goal is often predefined, and thus the job of the developmentalist is to figure out how specific changes at different points in development are relevant to the progression towards the goal. For example, Piaget's theory describes child development as proceeding towards a goal of formal operations, characterized by scientific, hypothetico-deductive thought. Earlier types of thought are devel- 
opmentally inferior to later types. Similarly, in Kohlberg's (1969) theory of moral development, the child passes through several stages towards the goal of self-generated justice.

Traditional research on aging has been equally influenced by the assumption of a goal: death. Age-related change during adulthood has been conceived as the opposite of age-related change during childhood. Researchers interested in biological effects of aging noted specific agerelated changes in cell biology that could be classified along a scale of "senescence." Models of decline adapted from biology were adopted by gerontological psychologists. The older adult's decline was described as a connected series of losses in the direction of senility, lack of productivity, and ultimately death. Labouvie-Vief and Blanchard-Fields (1982) describe well the traditional conception of old age:

Questions of aging . . . become primarily questions of negative comparisons. Since adulthood was seen as the achievement of an apogee, little room was left for growth and reorganization; rather, adulthood becomes merely a period characterized by stability at best. Change in adulthood, however, was usually conceived in negative terms, and attributed to decremental biological changes leading to an eventual breakdown of adaptive behavior (p. 185).

\section{Alternate Approaches to the Study of Gains and Losses}

Several theorists have expressed dissatisfaction with the traditional conception of gains and losses in developmental psychology. For example, Kagen (1980) criticized the traditional focus on what he called derivative change, and argued for other types of changes (losses) that could occur during childhood. Kagen asserted that the processes of replacement and disappearance, both of which are types of loss, may play an important role in child development. Replacement refers to the loss of one structure or function when another takes its place; disappearance refers to the loss of a structure or function without replacement. Kagen provided several examples of how replacement and disappearance are or could be involved in developmental transitions. His consideration of these types of loss was motivated by his rejection of the assumption of continuity inherent in most traditional developmental theories. Similarly, Labouvie-Vief (1982) suggested that in childhood and adolescence "developmental transitions may display profound disjunctive features by which earlier modes of thought and action, in being superseded, become partially displaced as well as transformed"' (p. 164). Flavell (1972) considered the possible role of loss in his conceptualization of the forms of developmental transitions. Kagen (1980) asserted that continuity of development is often more a construction of the developmentalist than a description of the nature of development. 
Life-span conceptions of development. Based partly on these criticisms, the life-span perspective of developmental psychology has offered an alternate, integrated set of theoretical assumptions about the nature of development across the life span. Life-span theorists stress that "The process of development in any given class of behavior is complex, and not a simple movement toward efficacy such as incremental growth. Rather, throughout life development is always constituted by the joint occurrence of gain (growth) and loss (decline)" (Hetherington \& Baltes, 1988, p. 4).

Life-span conceptions of development are well articulated in a recent review by Baltes (1987). He suggests that the notions of multidirectionality and multidimensionality are key to the life-span perspective. In his conception, these terms "describe facets of plurality in the course of development [and] promote a concept of development that is not bound by a single criterion of growth in terms of a general increase in size or functional efficacy" (p. 614). A full understanding of development requires the consideration of many different domains. At any given point in the life span, some abilities or skills are increasing, and others are decreasing. Moreover, the life-span perspective does not posit a specific goal for development, other than successful adaptation to the environment in which a person lives.

As an example of multidimensionality and multidirectionality, Baltes discussed Cattell (1971) and Horn's (1970, 1982) conception of intellectual development across the life-span. Two dimensions of intelligence have different trajectories across the life span. Fluid intelligence, or problem solving skill, declines during old age. Crystallized intelligence, which includes knowledge that has been acquired, such as vocabulary and general information, continues to improve across the life span. According to the life-span perspective, adult intellectual development thus can be understood best in terms of the co-occurrence of losses and gains in components of intelligence.

Intellectual development during adulthood is one of the most clearly articulated examples of the utility of the emphasis on loss and gain that is a characteristic of the life-span perspective. However, there are numerous other domains of development that could benefit from incorporating both gains and losses. Consider, for example, the development of autonomy in adolescence. Traditionally, adolescence has been defined as a period of increasing gains in personal freedom; parents exert less and less control over the maturing adolescent (See Steinberg \& Silverberg, 1986). However, recent research suggests that this portrayal is only half of the story. Although the influence of parents decreases during adolescence, the influence of peers increases. Thus adolescents are not necessarily more autonomous than younger children. In Steinberg and Silverberg's words, 
For most boys and girls, the transition from childhood into adolescence is marked more by a trading of dependency on parents for dependency on peers rather than straightforward and unidimensional growth in autonomy. During this time, youngsters become more emotionally autonomous in relation to their parents: They adopt less idealized images of their parents, relinquish some of their childish dependencies on them, and form a more individuated sense of self. For the majority of young people, however, the development of emotional autonomy during early adolescence is accompanied by increasing susceptibility to the influence of age-mates. Indeed, eighth and ninth graders demonstrate less autonomy in relation to their peers than do younger adolescents ... (p. 848).

This quote demonstrates that the acquisition of autonomy is best conceived as a multidimensional process involving both gains and losses.

A second example of how the traditional focus on gains has led to oversights about losses concerns the life-span development of skill in sports, such as tennis. The main focus of the sports media is on perhaps the smallest fraction of tennis players who are good enough to compete nationally. In this group, a 40-year-old is considered a wise veteran, and only a player who displays dogged determination is able to continuc to compete past the mid-30s. But this description of age-related change in tennis skill may apply only to the small minority of players who receive media attention. Although age brings losses in physical quickness and power, many tennis players may continue to improve their game as they age because they focus more on the strategic aspects of the game. Perhaps it is only at the extreme limits of competition-the extremes that receive the most attention-that physical quickness is required.

One possible weakness in the definitions of loss and gain that we have used is that they fail to distinguish permanent and biologically based losses from losses that are more psychological and perhaps impermanent. One might argue that losses that occur in late life are more devastating than losses that occur in early life, or that gains that occur during late life are less important than those that occur in early life. We agree that physical gains are more common in infancy, and physical losses are more common in old age. But there is no reason to believe that these physical losses necessarily undermine the overall quality of a person's life. At any point in the life span, there are biologically based and psychologicallybased losses and gains, and an understanding of the influences of all of these types of change is needed to understand the nature of development.

Relations between gains and losses. Central to the understanding of the role of gain and loss in development is the relation between the two processes. We believe that life-span theorists have tended to assume that during carly life gains cause losses, and that during late life losses cause gains. In other words, even researchers interested in the life span as a whole have assumed that losses in early life are byproducts of gains, and that gains in late life are byproducts or compensations for losses inherent 
in biological aging. We argue instead that gains and losses are not necessarily causally related. Moreover, when gains and losses are causally related, the direction of causality should not be assumed to be determined by nor necessarily related to age. The possibility and direction of causality of gains and losses in development should be evaluated in the same way as other simultaneously occurring phenomena; causality should not be assumed on the basis of a simple relation.

There are at least four possible models of the relationship between gains and losses. The first two models do not assume that the processes are causally related. An unrelated phenomenon model predicts simultaneous gains and losses that follow the occurrence of other simultaneous but independent factors. A spurious phenomenon model predicts simultaneous gains and losses that follow the occurrence of a single other factor. The third and fourth models do assume that gains and losses are causally related. A suppression model assumes that gains precede and cause losses, and a compensation model assumes that losses precede and cause gains. It appears that researchers have assumed that the suppression model applies to the relation between gains and losses in early life, and that the compensation model applies to the relation between gains and losses in late life. We suggest that there are alternate interpretations of age-related change that are equally plausible. The alternative interpretations provide new insights into the antecedents of particular developmental transitions.

\section{EXAMPLES AND INTERPRETATION OF GAINS AND LOSSES ACROSS THE LIFE SPAN}

In this section we consider three examples of development that can best be interpreted as the combined effect of gains and losses. In order to show the applicability of our arguments across the life span, the examples were deliberately chosen from different periods of life. Fach example considers the value of conceptualizing development as consisting of both gains and losses, and of relinquishing assumptions about age-determined causal relations between gains and losses. Figure 1 illustrates the general nature of the developmental trajectory of gains and losses that is discussed in each section.

We have limited our primary examples to the individual, psychological level. However, the gain/loss argument may apply equally to different levels of the analysis. For example, we believe our arguments are applicable to considerations of the course of relationships and social institutions. As relationships develop, the individuals involved give up some behaviors and beliefs and gain others. Similar arguments also have been made for understanding historical processes (Nisbet, 1980), and one could 


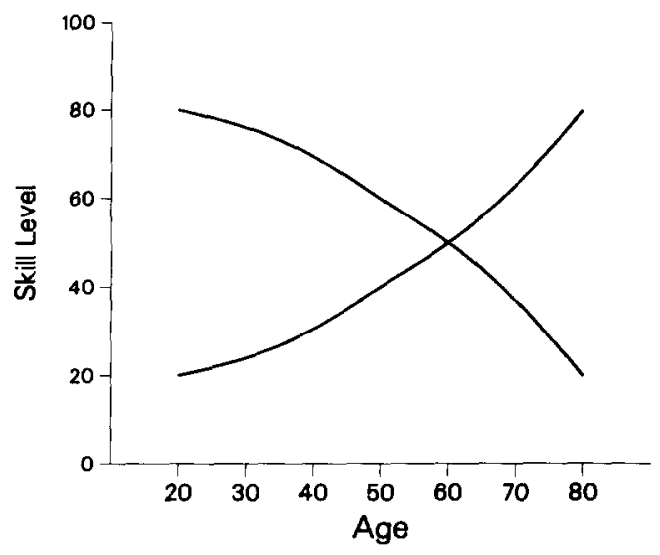

FIG. 1. Conception of development: Loss and gain.

conceive of the development of businesses and other organizations in terms of constant losses and gains; at any given point, some aspects increase, and others decrease.

Gains and Losses in the Development of the Neonatal Nervous System

Development of the neonate's nervous system provides a concrete example of the importance of both gains and losses in development even in early life. Development of many areas of both the central and peripheral nervous system consists of an overproduction of synapses (connections between neurons or between neurons and receptors) followed by a gradual decline in the number of synapses. While the number of synapses decreases, however, other aspects of the nervous system, such as myelinization, increase. In Nowakowski's (1987) words, "it is of great interest (and some irony) that an important set of processes during the development of the nervous system, which is generally thought of as being a series of progressive events, are regressive events involving the retraction of axons and the death of cells"' (p. 587). Examples of gains and losses in neonatal nervous system development illustrate that losses are characteristic of age-related change even at early periods of the life span. However, researchers have not assumed that these losses and gains are causally related. Loss and gain in the development of the nervous system thus can serve as a model of loss and gain in psychological development; loss and gain are both involved but are not necessarily causally related.

Gains and losses in neuromuscular connections. One example of the role of gains and losses involves the development of neural connections between terminal afferent neurons and muscle fibers. Skeletal muscular action is controlled by nerves that branch outward from the spinal cord. 
Histological examination and electrophysical stimulation experiments have shown that the pattern of connections between neurons and muscle fibers is quite different in neonatal and adult monkeys. In the neonate, a single neuron connects to several different muscle cells. In the adult, however, a single neuron connects to only one muscle cell (Purves \& Lichtman, 1980). An interesting developmental process is responsible for this difference. During prenatal development synapses are overproduced; the adult pattern is obtained through the loss of the multiple connections. A relatively chaotic pattern, characterized by many synapses with multiple connections, is replaced developmentally by a more efficient, precise system, in which the contraction of a single muscle fiber can be controlled more accurately (Purves \& Lichtman, 1980). Thus, attainment of adult structure and function depends both on overproduction and on subsequent loss of synapses. Through the loss of synapses, the infant gains more specific motor control and better coordination.

The complete development of the neuromuscular system depends also on increases in the myelinization of nerve fibers. Myelin is a lipoprotein produced by special cells within the nervous system (oligodendrocytes). It insulates nerve fibers and thus allows for faster transmission of nerve signals. Myelinization increases throughout childhood, and provides the child with greater speed and reaction time in muscle movements (Nowakowski, 1987; Richardson, 1982). In sum, the coordinated and specified muscular actions of the adult is obtained through both gains and losses.

Gains and losses in prefrontal cortex. A far more complicated and less well understood example of complementary gains and losses in the nervous system involves the development of neural circuitry in the prefrontal cortex. Researchers are only beginning to understand the importance of this area of the brain, but it is believed to be associated with thinking, reasoning, and information storage (Goldman-Rakic, 1987). Development of neural circuitry in the prefrontal cortex thus may have direct implications for cognitive development (Fischer, 1987). Researchers have identified a pattern of overproduction and decline in the number of synapses in the prefrontal cortex similar to that described in the development of neuromuscular connections. In rhesus monkeys the number of synapses in the prefrontal cortex begins to increase dramatically during the final third of gestation. The increase continues after birth, reaching a peak between 2 and 4 months postnatal. After four months, overproduction ceases, and the number of synapses subsequently declines gradually until adult levels are reached (Goldman-Rakic, 1987; See also Huttenlocher, 1979 , for a description of synapse loss in human cortex).

This pattern of synapse production and subsequent decline may be related to important milestones in cognitive development. One example involves a particular area in the prefrontal cortex that is associated in 
rhesus monkeys with performance on delayed response tasks. To investigate the importance of the spurt in synaptogenesis in this area, Goldman-Rakic (1987) devised a task similar to Piaget's A not B task, in which infants must first wait and then search for a displaced object. At four months the monkeys acquire the ability to maintain a representation of the displaced object. Goldman-Rakic suggested that the growth spurt in the number of synapses corresponds specifically to the emergence of the ability to represent mentally the location of the displaced objects. Goldman-Rakic drew analogies to the development of the prefrontal cortex in human infants and performance on Piaget's task.

The complete development of the prefrontal cortex and the abilities with which it is associated may also depend on the subsequent decline in the number of synapses. Specific demonstrations of the significance of the decline in the number of synapses in normal development are difficult to obtain, but researchers have suggested that the loss of synapses may be associated with gains in control or regulation of the abilities that emerged during the initial increase in synapses (e.g., Goldman-Rakic, 1987; Greenough, 1986; Rakic, Bourgeois, Zecevic, Eckenhoff, \& GoldmanRakic, 1986). Some forms of mental retardation have been linked to increased numbers of synapses (Cragg, 1975). The notion that important abilities such as mental representation may emerge before the ability to regulate and control these abilities is central in much current theory and research on children's cognitive development (for example, Gelman, 1978; Gelman \& Baillergeon, 1983; Hasher \& Zacks, 1979). The examples discussed here raise the possibility that this increase in control may be associated with a decrease in the number of prefrontal synapses. Figure 2 shows our conception of gains and losses in the development of the nervous system.

The processes involved in the development of neural circuitry are in some ways analogous to processes described in other domains of development and emphasized particularly by the life-span perspective. For example, one hypothesis of life-span developmental psychology is that plasticity is greatest early in life and decreases gradually throughout the life span (Baltes, 1987; Lerner, 1984). Researchers (Greenough, Black, \& Wallace, 1987; Purves \& Lichtman, 1980) have suggested that the pattern of overproduction of synapses followed by decline may have evolved as a means of providing plasticity in neural circuitry. Initially, many connections are redundant, but as the number of synapses declines, only those most useful in the environment in which the organism will live are preserved (See Greenough, 1986). Although the loss of the synapses is positive in that it is necessary for development of an optimally efficient nervous system, there is also a negative component: loss of redundant 


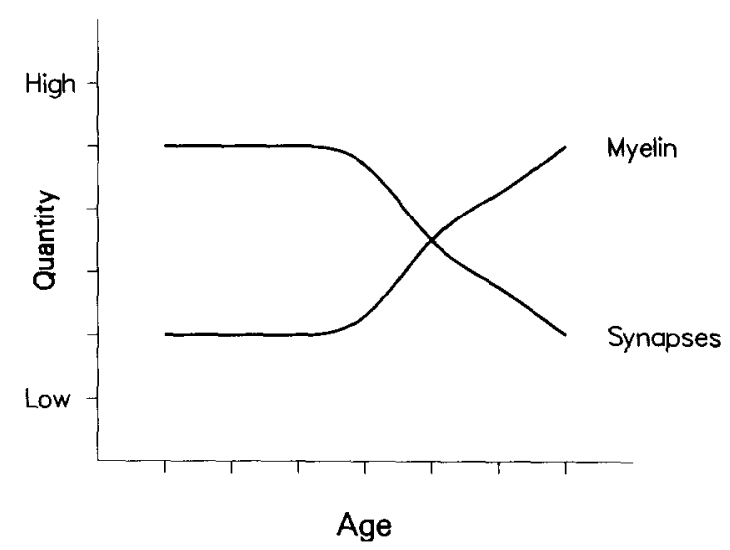

Fig. 2. Loss and gain in neonatal neural development.

synapses dictates that the organism loses possible alternative courses of development. According to Greenough et al. (1987), "At the neural level, the irreversibility appears to arise in at least some cases because a set of synapses has become committed to a particular pattern of organization, while synapses that could have subserved alternative patterns have been lost"' (p. 546).

Gains and Losses in Development of Children's Problem Solving Skills

Because of the growing popularity of the life-span perspective in psychology, the possibility of growth during old age seems less strange than it did only a decade ago. Although the majority of psychological research that is framed within the life-span perspective has focused on old age, the life-span perspective suggests that decline may occur during childhood. In the following section we discuss the most commonly cited example of loss during childhood, Weir's (1964) work on the development of problemsolving strategies. Researchers have suggested that the growth of more advanced styles of problem solving in childhood may lead to the decline of less advanced strategies. After presenting Weir's findings, we offer an alternate interpretation that does not assume necessarily causal relations between gains and losses. Specifically, we believe that the assumed causal relation between gains and losses may be spurious; in child development, both observed gains and losses noted by Weir may be the result of changes in cognitive styles and processing engendered by the separate, far-reaching influence of schooling.

In Weir's research (Stevenson \& Weir, 1963; Weir, 1964), subjects (ages 3 to 19) were presented with a row of three knobs and asked simply 
to push the knob that resulted in the presentation of a marble. The task was complicated, however, by the manipulation of the probability of payoff. In some conditions, pushing the correct knob resulted in the presentation of a marble $33 \%$ of the time, and in other conditions a marble was presented on $66 \%$ of the correct pushes. The probabilistic nature of reinforcement made the task deceptively difficult. When learning which knob to press, there was no clear solution. The performance of younger and older subjects in these experiments illustrates an important phenomenon that may shed light on the life-span dynamics of gains and losses.

Specifically, the performance of subjects from ages 7 to 15 was worse than that of either older or younger subjects (See Fig. 3). Different strategies accounted for the differences in performance. Younger subjects responded on the basis of a simple reinforcement notion. They were not planful, but instead simply hit the buttons until they found the correct one, and then hit that one on successive trials. Weir suggested that younger children "may expect neither complex nor perfect solutions in a task of this sort, and bchave accordingly" (p. 477).

School-aged children, on the other hand, appeared to have dramatically different expectations. Weir noted that they

enter this task with a strong expectancy that there is a solution which will yield $100 \%$ reinforcement, or at least $100 \%$ predictability of when a reinforcement will be delivered and when it will not, and employ complex strategies based on complex hypotheses concerning the nature of the task and the reinforcement schedules (p. 478).

Adults eventually deduced the nature of the task and gave up attempting to find a perfect solution. School-aged children, however, doggedly persisted in optimization strategies that were ineffective. One common

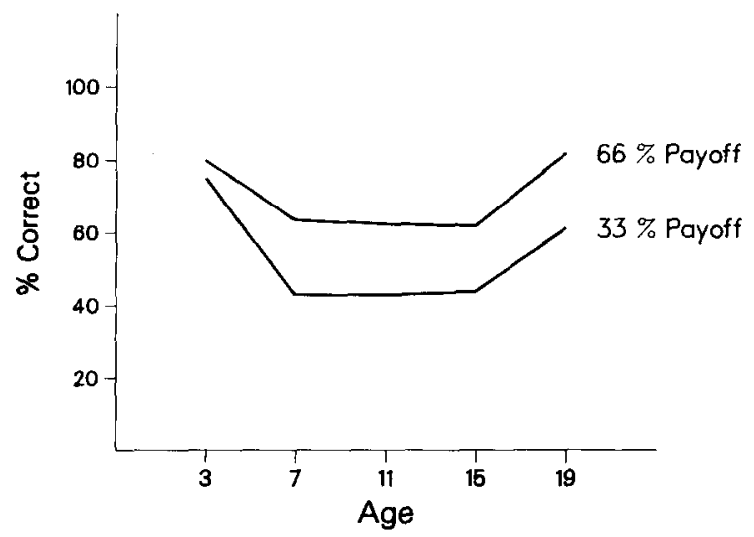

FIG. 3. Weir's (1964) results on the probability learning task. 
strategy was to repeat a pattern, such as left, middle, right. Some subjects memorized extremely complex sequences with as many as 10 separate responses (Stevenson, 1972).

Weir's experiments are a favorite of life-span theorists because they demonstrate clearly that development during childhood is not all gain. The results, however, seem to have been interpreted in terms of a causal relation between gains and losses. Baltes (1987), for example, interprets Weir's results as follows: "This work shows that higher-level cognitive functioning (associated with the so-called optimization strategy) can have its costs when the task in question has no perfect solution" (p. 617). The statement that one strategy "can have its costs" implies that gains and losses are causally related; that is, that in this instance of early development gains cause losses. This example thus would represent an instance of the suppression model.

We believe that there are alternate, equally plausible interpretations. For example, schooling might cause both the observed gains and losses. Differences in children's thinking that emerge during the early elementary school years (the 5-7 shift-see White, 1965) are among the most consistent and pervasive in the study of cognitive development. The dramatic effects of beginning schooling on the cognitive, social, and emotional development of children has been noted by numerous researchers (e.g., Gay \& Cole, 1967; Laboratory of Comparative Human Cognition, 1983; Rogoff, 1981; Stevenson, Parker, Wilkinson, Bonnevaux, \& Gonzales, 1978). Schooling can lead to shifts in emphasis of cognitive abilities. Children are taught to apply their thinking to tasks that are not immediately relevant to their environment. Almost all theories of cognitive development view this age period as a time of important transition. Some researchers have raised the possibility that beginning schooling may be an important factor in this shift (e.g., Skeen \& Rogoff, 1987; Stevenson et al., 1978; White, 1965). For example, Stevenson et al. (1978) investigated the effect of schooling and age on the cognitive performance of children in two geographically and culturally distinct areas of Peru. Samples of schooled and unschooled children of the same age (5 and 6) were compared. This design allowed Stevenson et al. to consider the additive and interactive effects of schooling and age. The effect of schooling was equal to or greater than the effects of age for most tasks. Figure 4 shows our conception of how schooling could lcad to both gains and losses.

From the life-span perspective, the effects of schooling can be interpreted as a shift in the trajectories of many different abilities. One would expect that dramatic events of the magnitude of those involved in schooling would lead to both gains and losses. It seems likely that children's belief in the existence of a perfect solution to Weir's task could be the result of going to school, where children typically are taught to look for 


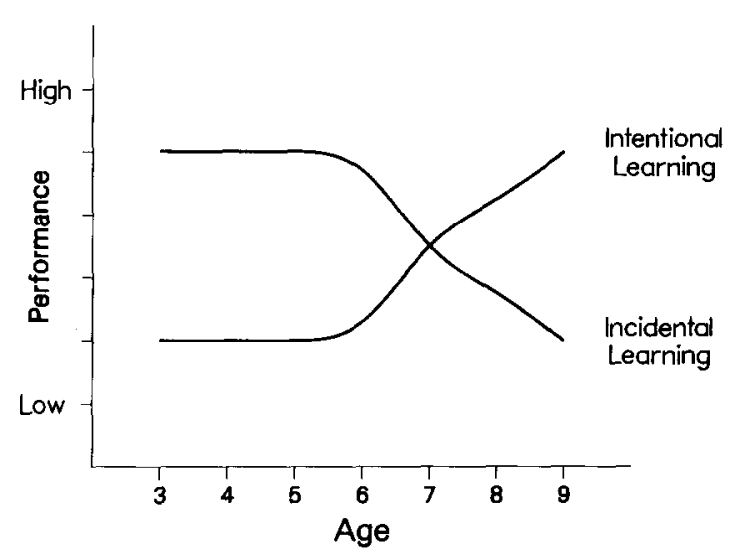

FIG. 4. The effects of schooling on gains and losses.

specific, perfect solutions. Indeed, the idea that children are taught that there must be a perfect solution to a problem has emerged as a central criticism of American education, and has led to the development of new curricula and teaching strategies that emphasize the ambiguity of realworld problems (See Segal, Chipman, \& Glaser, 1985). Classes have been instituted in which children are taught to think critically about problems that have no perfect solution.

The emergence of new strategies of problem-solving is analogous to development of the neonate nervous system. At first, there is a rapid emergence of new synapses (new strategies). Complete development of the nervous system depends on the loss of redundant synapses; complete development of problem-solving skills depends on the loss of the tendency to overapply newly acquired, higher level strategies.

Research on other learning domains demonstrates that decline in the performance of elementary school children is not confined to the threechoice probability learning task. For example, research on children's and adults' incidental learning has shown that incidental learning declines in some tasks as other types of learning emerge. A study by Maccoby and Hagen (1965) is perhaps the best known, although other researchers (e.g., Crane \& Ross, 1967; Siegel \& Stevenson, 1966) have obtained similar results using different methods. Children in grades 1, 3, 5, and 7 were asked to memorize the location of different cards in a series. Cards were identified both by a colored dot and a picture of an animal or household itcm. Children were told to remember the location of the different colors; they were not given instructions about remembering the location of the pictures. Children's memory of the picture locations therefore was a measure of incidental learning. 
Intentional learning increased with age, but the relationship between age and incidental learning was curvilinear. Seventh-graders remembered the location of significantly fewer pictures than did younger children. In other words, children's performance on the incidental learning task declined as performance on the intentional learning task increased. Other research supports the present contention that these developments may be caused at least in part by schooling (See Wilkinson, Parker, \& Stevenson, 1979).

Maccoby and Hagen's (1966) interpretation of their results, and additional interpretations by Hagen (1967) and Stevenson (1972), point to the relevance of the relation between intentional and incidental learning to the dynamics of gains and losses across development. These investigators suggested that older children's good performance on the intentional learning task and relatively poor performance on the incidental learning task indicates that younger children have not yet developed the ability to selectively attend to the relevant dimensions of the task. In other words, younger children are distracted by the incidental stimuli, and thus inappropriately assign their limited attentional resources to learning irrelevant stimuli. Older children devote their attention selectively to the intentional material, focusing on learning the colored dots at the expense of the incidental stimuli. The development of selective attention therefore can be described as the combined outcome of an increase in intentional learning and a decrease in incidental learning. Certainly schooling could influence this development; children must learn to focus selectively on the problem at hand (Wilkinson et al., 1979).

Other research of this kind is consistent with the interpretation that both gains and losses can be related to schooling. Spatial skills are one specific domain in which schooling may lead to loss. For example, Skeen and Rogoff (1987) investigated the effect of different types of instructions on children's spatial learning. Five-, seven-, and ten-year-olds explored a large playhouse containing several rooms under three conditions. In the Remember condition, children were asked to remember the location of the rooms as they explored the playhouse. In the Activity condition, children were asked to unroll a large ribbon as they walked through the playhouse. In the Remember-plus-Activity condition, children were asked to remember both the location of the rooms and to unroll the ribbon.

Seven- and 10-year-olds assigned to the Remember condition remembered the location of significantly fewer playhouse rooms than same-aged children assigned to the Activity conditions. Five-year-olds' performance did not vary by condition. Skeen and Rogoff suggested that 7 -year-olds in the Remember condition attempted to apply inappropriate memory strategies, such as remembering a list of the rooms rather than using a spatial strategy more appropriate for the task. They argued that the tendency to 
use list strategies could be the result of schooling, in which children focus their cognitive abilities on learning lists of materials. One finding consistent with this conclusion is that schooled children in the Peruvian highlands performed significantly worse on three of four spatial tasks than same-aged unschooled children (Barber, Uttal, \& Stevenson, 1987). As children apply their thinking to new types of problems, whether in school or in other situations, performance can decline in other domains. It should be noted that some researchers have observed very dramatic effects of schooling after only a few months (See Laboratory of Comparative $\mathrm{Hu}$ man Cognition, 1983).

\section{Gains and Losses in Adults' Cognitive Performance}

Most discussions of the relation between gains and losses in old age seem to suggest that gains are caused by losses. Researchers have suggested that older adults gain new skills as a result of, or to compensate for, biologically based losses. These interpretations typically imply that the loss precedes and at least indirectly causes the gain. For example, Baltes (1987) describes old age as a time of selective optimization with compensation, in which people refocus their efforts and abilities in order to maintain functioning despite age-related decline. In Baltes' (1987) words, one of the features of selective optimization with compensation is "individual selective and compensatory efforts dealing with evolving deficits for the purpose of mastery and effective aging"' (p. 616). This quote demonstrates the implicit assumption that losses during old age cause gains.

Other discussions of the relation between gains and losses also seem to imply that gains occur in response to loss. Pascual-Leone (1983), for example, suggested that changes in adult thinking are brought about largely because of physiological decline in operators, which are cognitive structures that influence thinking. He suggested that a decline in the $I$ (interrupt) operator begins in the mid-30s. The purpose of the $I$ interruptor is to repress conflicts resulting from beliefs that may be logically inconsistent. Regression of the operator causes a crisis (e.g., the mid-life crisis) because the individual no longer can repress the inconsistent beliefs. Pascual-Leone argued that "the individual faces up to conflicts within his or her ego structures that were already there but heretofore could be avoided by interruption of the undesirable partial selfs. Now interruption is no longer effective and a disequilibration (in the sense of Piaget), or the anxiety that goes with it, prompts the organism to seek a way of resolving the contradictions"' (p. 141). Similarly, Pascual-Leone suggested that new styles and contents of thought emerge in old-age because of the regression 
of other operators. He assumed that a new style of problem resolution (a gain) emerges because of and is caused by a loss in the strength of the operators.

The idea that gains in later adulthood are caused by biologically based losses is also apparent in empirical work. Perhaps the best-known example is Salthouse's (1984) research on the effects of age and experience on typing skills. The skills involved in typing are relatively easy to investigate as separate components, and thus it is possible to determine precisely which of the component processes are affected by age and experience. In addition, skilled typing provides a domain in which to investigate an expertise that has been acquired in a natural context. Some researchers have suggested that older adults may perform worse than younger adults in traditional comparisons simply because the older adults have had less experience with the experimental method or setting. These differences should be less important in the study of typing skills because the task is very familiar to typists of all ages.

Salthouse used a variant of Charness' (1981a, 1981b) molar equivalence-molecular decomposition experimental design to investigate the independent and interactive effects of age and experience on typing speed. Subjects were sampled from a wide range of age and experience levels so that the correlation between age and overall performance on the dependent variable approached zero. This method allowed Salthouse to determine how different components of typing skill were affected by age and by experience. Salthouse found interesting age and experience differences in the components of typing that suggest the influence of both gains and losses in the maintenance of a skill across the life span. Salthouse's research also illustrates the need for caution in inferring a particular causal direction between gains and losses.

One important component of typing speed that Salthouse investigated is reaction time: the amount of time needed to perceive a letter and decide which key to strike. A second component was keystroke speed: the amount of time needed to move the finger. Salthouse also recognized that skilled typing involves more than simply perceiving individual letters and striking individual keys. Skilled typists often respond in units; familiar words, for example, are typed faster than unfamiliar words. Thus another important variable in typing is preview span: the number of characters that the typist previews before typing a character. If more letters are previewed the probability of perceiving familiar blocks of letters (i.e., words) is increased. When the number of words that can be previewed is reduced by experimental manipulation, such as by controlling the number of characters available for preview, typing speed is reduced dramatically. Moreover, skilled typists have been found to preview on average almost 
a third more letters than less skilled typists (Salthouse, 1984; Shaffer, 1976).

Controlling for level of experience, Salthouse found that older typists had significantly slower reaction time and keystroke speed than younger typists. However, the two groups did not differ in overall typing speed. It appeared that an age difference in the range of preview accounted for the overall equivalent performance of older and younger typists. That is, older typists had significantly greater preview spans, and therefore showed no deficit in their overall typing speed.

There are at least two possible interpretations of the mechanisms involved in the maintenance of typing speed in older typists. The first interpretation is a compensation model: Loss in reaction time and keystroke speed are assumed to cause gain in the range of preview. In Salthouse's (1984) words:

The existence of a significant relation between age and eye-hand span, independent of the relation between span and skill, suggests a possible mechanism that may allow older typists to compensate for lower perceptual-motor efficiency . . . That is, the span may be larger because the older typists have adapted to their slower rates of processing by planning further ahead, in effect, scheduling around the bottlenecks in the system as much as possible (p. 369).

Salthouse did not specify exactly how this compensation could occur, but presumably the typist either consciously or unconsciously begins to focus on expanding the range of preview. This interpretation is often cited by life-span theorists as an example of possible gains in old age. Baltes (1987), for example, notes that older typists "cope with their loss in reaction time when typing individual letters by developing more extensive forward-processing of letter and word sequences"' (p. 617). Again, this interpretation seems to assume that losses precede and cause gains.

An alternate interpretation rests on the opposite (or no) assumption of a causal relation between loss and gain; that is, that gains and losses may be unrelated phenomena, or that a gain might actually cause a loss. The unrelated phenomenon model assumes that the gain in range of preview reflects a change in typing skill that results from experience, irregardless of reaction time and keystroke speed. Several researchers have demonstrated that increased experience in a specific skill (e.g., chess) can lead to qualitatively different ways of representing or processing information relevant to the skill (Anderson, 1982, 1987; Chi, Glaser, \& Farr, 1988). We believe that some aspects of typing skill (e.g., letter span) may improve simply through practice, thus maintaining typing speed overall. Simultaneously, but perhaps coincidentally, increased experience can lead to increased letter span, and increased age may lead to increased reaction and keystroke time. Figure 5 illustrates our conceptualization of 


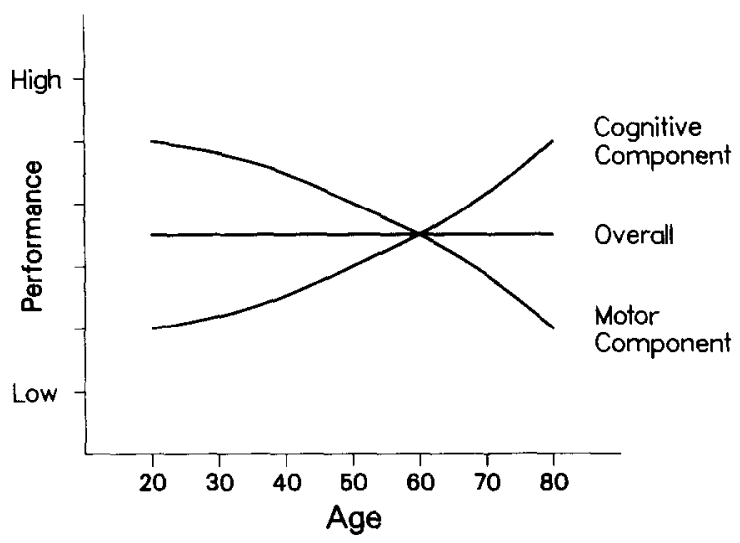

FIG. 5. The relation between age and different skills related to typing speed.

this relation. Over the adult years, efficacy in basic skills (reaction time and keystroke speed) may be lost, and efficacy of higher level processes (eye-hand span) may be gained. The cumulative result of these processes, which may or may not be independent, would be maintenance of overall typing speed.

Salthouse considered this interpretation, but stated that he preferred the first (compensation) interpretation. We believe that the second interpretation (unrelated phenomenon) seems at least equally plausible. In Salthouse's study the correlation between age and years of typing experience was quite high (.55), and thus one would expect that additional effects of experience would most likely be observed in the older subjects. One could argue that if the letter span increase is due to increased experience, then very experienced younger typists should also exhibit high letter span. Even if this pattern were not observed, however, a compensation explanation might not be appropriate, because all forms of experience may not be equal. Relatively intense experience, in which individuals practice typing extensively over a relatively short period of time, probably does not lead to the same type of expertise as the same total amount of practice distributed over a much greater period of time (Rybash et al., 1986). If acquisition of some forms of an expertise depend upon this type of distributed experience, then the acquisition of that expertise must occur over time and be related to age.

This interpretation is consistent with the theoretical work of Rybash et al. (1986) and Perlmutter (1988a, 1988b), who have proposed theories of cognition across the life span. They suggested that in childhood and adulthood, cognition is devoted primarily to the acquisition of knowledge, whereas in later adulthood, the primary focus is on the use and develop- 
ment of skills acquired earlier. Because older typists have practiced their skills daily, they may have come to rely more heavily on higher level processing; such a process shift is characteristic of the move from novice to expert. In Adams (1987) et al.'s words, "The implication here is that within those knowledge domains for which mature and older adults have developed an 'expertise', processing efficiency should not only be maintained, but in addition, a shift would be expected toward the spontaneous activation of processing mechanisms which are more heuristic, integrative, and knowledge-based"' (pp. 25-26). Rybash et al. (1986) refer to the process of focusing and developing specific domains as encapsulation; adult cognition focuses on maintaining and expanding extant knowledge within specific domains. Consequently, knowledge within specific domains becomes "more differentiated, accessible, usable, and 'expert' in nature"' (Rybash et al., 1986, p. 17; see also Backman, 1985).

The pervasiveness of the compensation model of gains in old age, and the relevance of the present interpretation, is further demonstrated in Charncss' (1981b) investigation of the effects of age and experience in performance at chess. Charness found that older chess experts performed worse than younger experts in standard memory tasks, yet older experts were able to search through a series of possible moves, a critical skill in chess. In interpreting these results, Charness noted, "Thus we have the paradoxical situation that older players have less efficient memory processes, as judged by recall tasks, yet more efficient search processes, as judged by move selection." He then asked "What compensatory mechanisms do older players rely on?" (p. 20). Charness realized that additional expertise may be acquired with age; he stated that "over the thousands of hours that they [older chess experts] have spent searching for moves, they too may have developed elaborate retrieval structures that enable them to chunk sequences of moves thereby enabling them to search deeply" (p. 21). However, like Baltes, Pascual-Leone, and Salthouse. Charness seems to imply that this gain in depth of search is applied only as compensation for loss.

One example of the alternative interpretation of gains in old age comes from research on narrative processing by Adams, Labouvie-Vief, Hobart, and Dorosz (1987). These researchers suggest a possible shift across the life span in the interpretation and derivation of meaning from narrative text. When asked to recall and/or summarize a story, for example, adolescents and younger adults tend to focus on the literal meaning contained in the story's propositional context, whereas midlife and older adults shift their focus to the moral implications (Adams, 1987; Adams et al., 1987). This difference was not interpreted as compensation, but rather as the result of the emergence in older adulthood of alternate ways of deriving meaning from narratives. 


\section{ALTERNATE APPROACHES TO RESEARCH}

In this section we consider the implications of the present perspective for research. A view of development that emphasizes losses and gains implies several modifications in the ways that developmental research should be conceptualized, developmental studies should be designed, and developmental data should be analyzed. A first research step involves identification of gains and losses that might occur at various portions of the life span. We believe that a greater focus on the context in which development occurs will make more obvious the presence of gain and losses because it will force researchers to consider in more detail the relevance of the developmental transition to the individual's life.

Several interpretations of the word context are relevant. The first concerns the relevance of the researchers' tasks to the individuals being studied. For example, a very different interpretation of the overall effect on older adults' competence is reached depending upon whether the researcher interprets observed losses in the context of the laboratory or on a job. In the former context, the focus, by default, is on losses; gains are rarely observed, we believe at least in part because research typically has not been motivated by assumptions that gains occur in old age. On the other hand, Salthouse's research indicates that far different conclusions can be reached if overall performance is accessed in a context that is meaningful to the individual-in this case, on the job. Salthouse found that although older typists perceived and typed individual letters more slowly, their overall typing speed was not affected. We suggest that a fruitful direction for research is to consider losses and gains that are involved in the maintenance or increase in job performance in other professions (e.g. Perlmutter, Kaplan, \& Nyquist, 1987).

A second meaning of context concerns the relevance of particular lifeevents to development. Considering the importance of major life events can help to highlight the presence of losses and gains. This suggestion is consistent with what Baltes (1987) has called "age-graded" influences on development. For example, beginning school represents a major life transition for 6-year-olds. As we have discussed, living through this transition might lead both to losses and gains. Researchers might be much more likely to notice both losses and gains if they considered their findings (e.g., the apparent loss in clcmentary school children's problem-solving skills) in terms of the contextual influences on their subjects' performances.

Culture and history are two additional senses of context that are relevant to a perspective that emphasizes losses and gains. What appears as a gain in one culture may be considered a loss in another. For example, researchers from western cultures might consider only the gains associ- 
ated with schooling. However, members of other cultures might focus more on possible losses, such as those associated with removing the child from the work force during school hours, and perhaps limiting the child's acquisition of job-relevant skills. Similarly, within a single culture, a gain at one point in history might be considered a loss at another point. For example, prior to the introduction of printing, human memory was the only vehicle for carrying individual and communal knowledge through time and space (See Olson, 1977; Perlmutter, 1988c). The art and skill of memory was extremely valued, and the mnemonist much admired (Yates, 1966). As everyday needs for memory diminished, previous intrigue with memory skill declined and the status of the mnemonist changed. Indeed, around the 16th century strong memory assumed its present implication of weak judgment (Boorstin, 1983).

\section{Research on "U-Shaped Curves"}

The value of the present perspective for conceptualizing research issues also can be illustrated by considering research conducted under the rubric of "U-shaped curves." In a "U-shaped curve" phenomenon, children's performance begins at a relatively high level, decreases with age, and then returns back to or exceeds the original performance level. This research (e.g., Bever, 1982; Strauss \& Stavy, 1982) is relevant because it represents an attempt to understand an apparent loss during child development. Reinterpreting research on U-shaped curves demonstrates the value of conceptualizing research issues from a perspective that emphasizes simultaneous gains and losses.

Strauss and Stavy (1982) suggested that the U-shaped curve phenomenon is important in studying children's cognitive development. In several domains, such as children's understanding of the Fahrenheit temperature scale, development follows a U-shaped pattern. Strauss and Stavy indicated that the decline portion of the U-shaped curve represents a transition from a relatively simple, experience-based conception of the temperature scale to a more abstract understanding of the nature of heat, temperature, and measurement in general.

However, to suggest that development in any domain can be modeled as a single curve, either straight or U-shaped, is to miss the point. Children's performance on the single measure under study could indeed be described by a $U$ shape, but the finding is an artifact of the combined effect of losses and gains. While one style of problem-solving emerges, another may decline. Attempts to describe development as any single curve do not capture the essential multidimensionality of human change.

Klahr (1982) realized that the U-shaped curve phenomenon was an artifact of the way in which success or failure were defined in the exper- 
iment. His refutation of the importance of U-shaped phenomena, however, also demonstrates the apparent pervasiveness of the assumption that development is unidirectional. Klahr argued that U-shaped curves are a molecular description of a process that represents, at a molar level, a developmental increase. To support his contention, Klahr discussed an example not related to psychology in which "age-related" change appears $U$-shaped at first glance but actually is not.

Klahr's example concerns the organizational development of a bank. If the performance of the bank is defined as the amount of time needed to obtain a loan, the development of the bank will take the form of a Ushaped curve. This pattern occurs at first because the bank is likely to have only one office, capable of handling all loan applications within a day. In the next stage, the bank adds several branches; loan applications at a branch now take several days to be processed because applications must be sent to the central office. The bank's performance, as defined as the time needed to obtain a loan, has therefore declined. But if at a still later stage the bank acquires a computer to handle loan requests, performance will improve dramatically, thus leading to the U-shaped curve. Klahr argued that focusing on the single measure of loan processing time leads to the mistaken belief that the bank experienced a performance decrease in the middle stage of development. Overall performance of the bank in fact increased, even if there was a temporary decline in a single measure.

Klahr argued that the bank example shows that the U-shaped curve description is meaningless: the bank only declined in a single measure on its way to becoming a more productive organization overall. We believe, however, that this example illustrates that gains and losses are both involved in any developmental change. From the perspective of the bank officer, the overall efficiency of the bank increased throughout all stages. But from the perspective of the customer who wished to have a loan approved, the bank experienced a strong "age-related" decline when it opened branches and began to take several days to process loan applications. Klahr argued that this loss was trivial, but it is interesting to note that the focus on increasing organizational growth at the expense of basic customer satisfaction is a central criticism of American business and has been suggested as one cause of the loss of competitiveness to foreign competition. The point is that the loss of customer satisfaction is a real loss; by the standard from which banks are typically judged (i.e., profit), the gains in organization development outweigh the losses, but the losses cventually can outweigh the gains and lead to the failure of the bank.

Determining Whether and How Gains and Losses Are Causally Related In the discussion of age-related change, both in adults' typing skill and 
children's problem solving skills, we suggested that gains and losses might not be causally related, or if causally related, might not be related in the typically assumed direction. The primary purpose of these examples was to demonstrate that age should not be assumed to determine the relation between gains and losses in development. Implicit in these discussions is the need for further research on the relations between gains and losses in development. The search for mechanisms of development should be expanded to include analysis of the dynamics and possible direction of causality of gains and losses.

How could one go about determining whether gains and losses observed in development are causally related, and, if causally related, the directionality of causality? Earlier we suggested that researchers apply the same criteria to the analysis of the relations between gain and losses as are applied in the analysis of any relation observed between two variables (See Campbell \& Stanley, 1966, for a description of these criteria). The researcher should of course consider whether the losses and gains observed are really unrelated phenomena. This consideration was raised in the discussion of Salthouse's (1984) research on typing skills. Losses observed in keystroke speed probably are caused by biological aging, whereas gains in range of preview may be caused by separate processes related to experience. The apparent relation of gains and losses that are observed may simply reflect the focus of the researcher. If Salthouse had focused only on overall typing skill across the life span, he would have found no significant differences between age groups.

Ideally, longitudinal data would be available. Salthouse suggests specific predictions about the nature of age-related change in the components of typing skill. The compensation model predicts that gains should emerge relatively quickly and later than losses; that is, that gains should be observed only after losses have become severe enough to inhibit overall typing speed. If observed gains are caused by, or are responses to, losses, then the curve of increases may be abrupt, rather than gradual, and subsequent to rather than simultaneous with the curve of declines. These predictions could be assessed most accurately by assessing component skills in the same individuals across the life span.

Collecting longitudinal data across the life span is of course extremely difficult and expensive. Fortunately, there are some issues related to typing speed that could be assessed using experimental or quasiexperimental methods. One issue is the mechanism by which older typists develop increased range of preview. One relevant hypothesis is that older typists choose to develop this new skill. This hypothesis could be tested by interviewing older typists. Were they aware of the declines in their perceptual and motor processes? If so, did they choose to compensate? Werc they aware of the advantage of an increased eye-hand span? If so, 
how did they learn this compensation, and how did they implement it into their day-to-day typing? Questions could also be addressed to novice typists of different ages. The model of gains and losses in typing skill that we prefer suggests that the expanded eye-hand span develops gradually with experience in typing. This view suggests that less experienced typists who were informed about the effects of span-length on typing speed might not find this information useful in improving their typing speed. This hypothesis could be tested by telling typists at different levels of experience about the eye-hand span advantage, and assessing the effect on typing performance across a period of several months.

Another possibility would involve including additional groups to form a complete age by experience factorial design. One limitation in Salthouse's design is that age and experience are confounded. Adding cells to complete a factorial design might help to separate the effects of these variables. Specifically, one could add to the design a group of older but less experienced typists, and a group of younger but expert typists. If decreases in keystroke speed are due to the effects of aging on perception and motor skills, and gains in preview span are due to the effects of increased experience, then younger, inexperienced typists should demonstrate fast keystroke speeds but short preview spans; younger experienced typists should demon'trate fast keystroke speeds and long preview spans. Older, experienced typists should show slow keystroke speeds but long preview spans; older, inexperienced typists should show slow keystroke speeds and short preview spans.

The issue of context also is important in considering gains and losses in typing skill. For example, a consideration of the historical context of typing skills research might lead to different perspectives on the observed losses and gains. One important historical difference between young and old typists is that old typists learned to type on manual typewriters, whereas many of the younger typists probably learned to type on electric typewriters. This difference might affect the relation between span length, finger movement, and overall typing speed. Another important point to consider is the factors that have led to the older typists maintaining their on-the-job performance. Would the same effect be observed in older typists who began typing at middle age? Are individuals who continue to maintain their on-the-job performance the healthiest older adults?

Similar issues are relevant in addressing the relation between gains and losses involved in the development of children's problem-solving skills. We suggested that schooling could cause both the gains and losses observed in problem-solving skill; that is, that the observed relation between gains and losses might be spurious. There are at least three types of studies that could be conducted to address this issue. The first would involve assessing, through longitudinal research, the rates of changes 
(both gains and losses) in children's problem solving skills. The spurious model predicts a rather quick and dramatic effect of schooling. This model could be tested by assessing children's skills for several months prior and subsequent to the time when they enter school. On the one hand, if schooling is the critical variable in determining both the losses and gains, then changes should be abrupt. On the other hand, if Baltes' (1987) and Weir's (1964) suppression model is correct, that is, if agerelated gains in thinking skills cause losses in other domains, then the observed change should be more gradual, and within any subject sample correlations between relevant variables should be large but negative.

Cross-cultural research also may be helpful in assessing causality and direction of causality in developmental gains and losses. In cultures where children begin school at different ages, the effects of schooling and age can be separated (See Stevenson et al., 1978; Stevenson, 1988). Studies could be conducted to address more directly the types of problemsolving skills that researchers (e.g. Weir, 1964; Baltes, 1987) have suggested decline as children gain new skills (See Wilkinson et al., 1979).

A third possible type of study to evaluate the relationship between gains and losses in children's problem-solving might entail assessing the effects of alternate types of schooling, such as Montessori or home schooling, on gains and losses. If schooling does cause both the observed gains and observed losses, we would expect less dramatic effects in children who have not attended typical schools. Although one might argue that these children would represent a highly biased sample it should be possible to test whether their cognitive abilities and personality characteristics are different from children who attend more typical schools.

\section{Analysis of Data Concerning Losses and Gains}

The existence of gains and losses implies a multivariate approach to gains and losses, and standard analysis of variance techniques may be inadequate to test the alternative hypotheses suggested in this paper. One intriguing alternative is structural equation modeling, which allows researchers to test specific hypothesis about presumed causal relations between different sets of variables (See Biddle \& Marlin, 1987; Kenny, 1979; Martin, 1987). Structural equation modeling could be particularly useful when longitudinal data is available, and can provide a much more satisfactory method of testing assumed causal relations than can more traditional methods, such as cross-lagged panel correlations (Gollob \& Reichardt, 1987; Rogosa, 1979, 1980). One could, for example, consider modeling one set of observed behaviors as indicators of a latent underlying variable of "losses" (e.g., laboratory-assessed perceptual-motor skills) and another observed set of variables (e.g., job-related increases, 
wisdom, vocabulary) as indicators of a latent variable of "gains" (see Joreskog, 1979; Rogosa, 1979). The researcher then could specifically test the assumption of causality between gains and losses, as well as the direction of causality.

\section{CONCLUSIONS}

This paper has presented several examples of how both gains and losses are involved in development during both early and late life. Understanding of these processes requires relinquishing the assumption that the occurrence, and possible causal direction, of gains and losses are necessarily tied to time of life. We have shown that development can be more comprehensively understood by viewing gains and losses as changes that occur throughout life, and by keeping open any conclusions concerning causality of gains and losses at all points in the life span. The notion in life-span interpretations that gains and losses are causally related, and that the direction of causality is determined by age, may be a vestige of the traditional assumption that late life is a time primarily of loss and that early life is a time primarily of gain.

Conceptions of the possible relations between developmental gains and losses probably will broaden as the life-span perspective matures. The life-span perspective on development is still a relatively new one. Because of the strong assumption that late life was a time of exclusive decline, a demonstration of the possibility of compensation in old age may have been a necessary first step towards research and theory considering other possible relations between gains and losses across the life span. Research that considers new gains (e.g., wisdom; see Baltes, 1987; Holliday \& Chandler, 1986) in old age that probably do not occur in response to loss illustrates the possibility of moving beyond a compensation model of growth in old age.

Speculatively we suggest that there may be an opposite and perhaps equal reaction to every loss or gain across the life span. Rather than simply documenting gains or losses, developmentalists should focus on the possible co-occurrence or reciprocity of such change. When improvements are observed, questions should be raised about possible complementary losses. Likewise, when losses are observed, questions should be raised about possible complementary gains. It is important, however, that in carrying out such analysis, researchers do not assume that the direction of causality is tied to time of life. Indeed, it should not even be assumed that such events necessarily are causally related. As we have shown, investigating alternative causes requires that the researchers consider the antecedents of both the observed gains and losses, as well as the context in which these changes occur. 
Many more developmental transitions need to be considered from a perspective that emphasizes both gains and losses. Of particular importance in this regard are further examples of losses in early life and gains in late life. Although such thinking may strike researchers and theorists as radical, we believe that the novelty of the approach will diminish with the emergence of new empirical evidence on the gains and losses experienced in both early and late life. We hope that this paper has offered a theoretical perspective from which to begin to collect such evidence.

\section{REFERENCES}

Adams, C. (1987). Styles of narrative processing: A qualitative shift from adolescence to mature adulthood. Paper presented at the annual meeting of the American Psychological Association, New York.

Adams, C., Labouvie-Vief, G., Hobart, C. J., \& Dorosz, M. (1987). Adult age group differences in story recall style. Unpublished manuscript, University of Michigan.

Anderson, J. R. (1982). Acquisition of cognitive skill. Psychological Review, 89, 369-406.

Anderson, J. R. (1987). Skill acquisition: Compilation of weak-method problem solutions. Psychological Review, 94, 192-210.

Bäckman, L. (1985). Compensation and recoding: A framework for aging and memory research. Scandinavian Journal of Psychology, 26, 193-207.

Baltes, P. B. (1987). Theoretical propositions of life-span developmental psychology. Developmental Psychology, 611-626.

Baltes, P. B., \& Reese, H. W. (1984). The life-span perspective in developmental psychology. In M. H. Bornstein \& M. E. Lamb (Eds.), Developmental psychology: An advanced textbook (pp. 493-531). Hillsdale, NJ: Erlbaum.

Barber, B. L., Uttal, D. H., \& Stevenson, H. W. (1987). The effects of location and schooling on the spatial abilities of Peruvian children. Paper presented at the annual meeting of the American Education Research Association, Washington.

Bever, T. G. (1982). Regression in mental development. Hillsdale, NJ: Erlbaum.

Biddle, B. J., \& Marlin, M. M. (1987). Causality, confirmation, credulity, and structural equation modeling. Child Development, 58, 4-17.

Birren, J. E. (1988). A contribution to the theory of the psychology of aging: As a counterpart of development. In J. E. Birren \& V. L. Bengtson (Eds.), Emergent theories of aging (pp. 153-176). New York: Springer.

Boorstin, D. J. (1983). The discoverers. New York: Random House

Bourgeois, J-P., Goldman-Rakic, P. S., \& Rakic, P. (1985). Synaptogenesis of prefrontal cortex: Quantitative EM analysis in pre- and postnatal rhesus monkeys. Society of Neuroscience Abstracts, 9, 692.

Campbell, D. T., \& Stanley, J. C. (1966). Experimental and quasi-experimental designs for research. Chicago: Rand McNally.

Cattell, R. B. (1971). Abilities: Their structure, growth, and action. Boston: Houghton Mifflin.

Charness, N. (1981a). Aging and skilled problem solving. Journal of Experimental Psychology: General, 110, 21-38.

Charness, N. (1981b). Search in chess: Age and skill differences. Journal of Experimental Psychology: Human Perception and Performance, 7, 467-476.

Charness, N. (1985). Cognition in everyday life: Research approaches, aging effects, and enhancement methods. Paper presented at the third George A. Talland Memorial Conference on Aging, New Seabury, MA. 
Chi, M. T. H., Glaser, R., \& Farr, M. (Eds.) (1988). The nature of expertise. Hillsdale, NJ: Erlbaum.

Cragg, B. G. (1975). The density of synapses and neurons in normal, mentally defective, and aging human brains. Brain, 98, 81-90.

Crane, N. L., \& Ross, L. E. (1967). A developmental study of attention to cue redundancy introduced following discrimination learning. Journal of Experimental Child Psychology, 5, 1-15.

Fischer, K. W. (1987). Relations between brain and cognitive development. Child Development, 58, 623-632.

Flavell, J. H. (1972). An analysis of cognitive developmental sequences. Genetic Psychology Monographs, 86, 279-350.

Gay, J., \& Cole, M. (1967). The new mathematics and an old culture: A study of learning among the Kpelle of Liberia. New York: Holt, Rinehart, \& Winston.

Gelman, R. (1978). Cognitive development. Annual Review of Psychology, 29, 297-332.

Gelman, R., \& Baillergeon, R. (1983). A review of some Piagetian concepts. In J. Flavell \& E. Markman (Eds.), Handbook of child psychology (Vol. 3, pp. 167-230). New York: Wiley.

Gentner, D. R. (1987). Timing of skilled motor performance: Tests of the proportional duration model. Psychological Review, 94, 255-276.

Goldman-Rakic, P. S. (1987). Development of cortical circuitry and cognitive function. Child Development, 58, 601-622.

Gollob, H. F., \& Reichardt, C. S. (1987). Taking account of time lags in causal models. Child Development, 58, 80-92.

Greenough, W. T. (1986). What's special about development? Thoughts on the bases of experience-sensitive synaptic plasticity. In W. T. Greenough \& J. M. Juraska (Eds.), Developmental neuropsychobiology (pp. 387-407). Orlando: Academic Press.

Greenough, W. T., Black, J. E., \& Wallace, C. S. (1987). Experience and brain development. Child Development, 58, 539-559.

Hagen, J. W. (1967). The effect of distraction on selective attention. Child Development, 38, 685-694.

Hasher, L., \& Zacks, R. T. (1979). Automatic and effortful processes in memory. Journal of Experimental Psychology: General, 108, 356-388.

Hetherington, E. M., \& Baltes, P. B. (1988). Child psychology and life-span development. In E. M. Hetherington, R. M. Lerner, \& M. Perlmutter (Eds.), Child development in life-span perspective (pp. 1-19). Hillsdale, NJ: Erlbaum.

Holliday, S., \& Chandler, M. (1986). Wisdom: Explorations in adult competence. In J. A. Meacham (Ed.), Contributions to human development (Vol. 17). Basel, Switzerland: Karger.

Horn, J. L. (1970). Organization of data on life-span development of human abilities. In L. R. Goulet \& P. B. Baltes (Eds.), Life-span developmental psychology: Research and theory (pp. 423-466). New York: Academic Press.

Horn, J. L. (1982). The theory of fluid and crystallized intelligence in relation to concepts of cognitive psychology and aging in adulthoud. In F. I. M. Craik \& S. E. Trehub (Eds.), New directions in cognitive science (pp. 69-87). Norwood, NJ: Ablex.

Huttenlocher, P. R. (1979). Synaptic density in human frontal cortex-developmental changes and effects of aging. Brain Research, 163, 195-205.

Jöreskog, K. G. (1979). Statistical estimation of structural models in longitudinal-developmental investigations. In J. R. Nesselroade \& P. B. Baltes (Eds.), Longitudinal research in the study of behavior and development (pp. 303-351). New York: Academic Press. 
Kagen, J. (1980). Perspectives on continuity. In O. G. Brim, Jr., \& J. Kagen (Eds.), Constancy and change across the life span (pp. 26-74). Cambridge, MA: Harvard University Press.

Kenny, D. A. (1979). Correlation and causality. New York: Wiley.

Kessen, W. (1984). The end of the age of development. In R. Sternberg (Ed.), Mechanisms of cognitive development (pp. 1-17). New York: Freeman.

Klahr, D. (1982). Nonmonotone assessment of monotone development: An information processing analysis. In S. Strauss \& S. Stavy (Eds.), U-shaped behavioral growth (pp. 63-86). New York: Academic Press.

Kohlberg, L. (1969). Stage and sequence: The cognitive developmental approach to socialization. In D. A. Goslin (Ed.), Handbook of socialization theory and research (pp. 347-480). Chicago: Rand McNally.

Laboratory of Comparative Human Cognition (1983). Human development in a crosscultural perspective. In W. Kessen (Ed.), Handbook of child psychology (Vol. 1, pp. 295-356). New York: Wiley.

Labouvie-Vief, G. (1982). Dynamic development and mature autonomy: A theoretical prologue. Human Development, 25, 161-191.

Labouvie-Vief, G. (1985). Intelligence and cognition. In J. E. Birren \& K. W. Schaie (Eds.), Handbook of the psychology of aging (2nd ed., pp. 500-530). New York: Praeger.

Labouvie-Vief, G., \& Blanchard-Fields, F. (1982). Cognitive aging and psychological growth. Aging and Society, 2, 183-209.

Lerner, R. M. (1984). On the nature of human plasticity. New York: Cambridge University Press.

Lerner, R. M., \& Kauffman, M. B. (1985). The concept of development in contextualism. Developmental Review, 5, 309-333.

Maccoby, E. E., \& Hagen, J. W. (1965). Effect of distraction upon central versus incidental recall: Developmental trends. Journal of Experimental Child Psychology, 2, 280-289.

Martin, J. A. (1987). Structural equation modeling: A guide for the perplexed. Child Development, 58, 33-37.

Nisbet, R. (1980). History of the idea of progress. New York: Basic Books.

Nowakowski, R. S. (1987). Basic concepts of CNS development. Child Development, 58, 568-595.

Olson, D. R. (1977). From utterance to text: The bias of language in speech and writing. Harvard Educational Review, 47, 257-281.

Pascual-Leone, J. (1983). Growing into human maturity: Toward a metasubjective theory of adulthood stages. In P. B. Baltes \& O. G. Brim, Jr. (Eds.), Life-span development and behavior (Vol. 5, pp. 118-156). New York: Academic Press.

Perlmutter, M. (1988a). Cognitive development in life span development: From description of differences to explanation of changes. In E. M. Hetherington, R. M. Lerner, \& M. Perlmutter (Eds.), Child development in life-span perspective (pp. 191-217). Hillsdale, NJ: Erlbaum.

Perlmutter, M. (1988b). Cognitive potential throughout life. In J. E. Birren \& V. L. Bengtson (Eds.), Emergent theories of aging (pp. 247-268). New York: Springer.

Perlmutter, M. (1988c). Research on memory: past, present, and future. In F. Weinert \& M. Perlmutter (Eds.), Memory development: Universal change and individual development. Hillsdale, NJ: Erlbaum.

Perlmutter, M. (1988d). Late life potential. Washington: Gerontological Society of America.

Perlmutter, M., Kaplan, M., \& Nyquist, L. (1987). Development of competence across adulthood. Paper presented at the biennial meetings of the International Society for the Study of Behavioral Development, Tokyo. 
Purves, D., \& Lichtman, J. W. (1980). Elimination of synapses in the developing nervous system. Science, 210, 153-157.

Rakic, P. (1986). Mechanisms of ocular dominance segregation in the lateral geniculate nucleus: Competitive elimination hypothesis. Trends in Neuroscience, 9, 11-15.

Rakic, P., Bourgeois, J-P., Zecevic, N., Eckenhoff, M. F., \& Goldman-Rakic, P. S. (1986). Isochronic overproduction of synapses in diverse regions of the primate cerebral cortex. Science, 232, 232-235.

Rakic, P., \& Goldman-Rakic, P. S. (1985). Development and modifiability of the cerebral cortex. Neuroscience Research Program Bulletin, 20, 429-611.

Richardson, E. P., Jr. (1982). Myelinization in the human central nervous system. In W. Haymaker \& R. D. Adams (Eds.), Histology and histopathology of the nervous system (Vol. 1, pp. 146-173). Springfield, IL: Thomas.

Rogoff, B. (1981). Schooling and the development of cognitive skills. In H. Triandis \& A. Heron (Eds.), Handbook of cross-cultural psychology (Vol. 4, pp. 233-294). Rockleigh, NJ: Allyn \& Bacon.

Rogosa, D. (1979). Causal models in longitudinal research: Rationale, formulation, and interpretation. In J. R. Nesselroade \& P. B. Baltes (Eds.), Longitudinal research in the study of behavior and development (pp. 263-302). New York: Academic Press.

Rogosa, D. (1980). A critique of cross-lagged correlation. Psychological Bulletin, 88, 245258.

Rybash, J. M., Hoyer, W. J., \& Roodin, P. A. (1986). Adult cognition and aging. New York: Pergamon Press.

Salthouse, T. A. (1984). Effects of age and skill in typing. Journal of Experimental Psychology: General, 113, 343-371.

Segal, J. W., Chipman, S. F., \& Glaser, R. (1985). Thinking and learning skills: Relating instruction to research (Vol. 1). Hillsdale, $\mathrm{NJ}$ : Erlbaum.

Shaffer, L. H. (1976). Intention and performance. Psychological Review, 83, 375-393.

Siegel, A. W., \& Stevenson, H. W. (1966). Incidental learning: A developmental study. Child Development, 37, 811-817.

Skeen, J. A., \& Rogoff, B. (1987). Children's difficulties in deliberate memory for spatial relationships: Misapplication of verbal mnemonic strategies? Cognitive Development, 2, 1-19.

Skinner, E. A. (1987). Life-span developmental psychology: Snapshot of an emerging field. Contemporary Psychology, 32, 1019-1020 (Review of L. Sugarman (1986). Life-span development: Concepts, theories, and interventions. London: Methuen).

Steinberg, L., \& Silverberg, S. B. (1986). The vicissitudes of autonomy in early adolescence. Child Development, 57, 841-851.

Stevenson, H. W. (1972). Children's learning. Englewood Cliffs, NJ: Prentice-Hall.

Stevenson, H. W. (1988). Culture and schooling: Influences on child development. In E. M. Hetherington, R. Lerner, \& M. Perlmutter (Eds.), Child development in life-span perspective (pp. 241-258). Hillsdale, NJ: Erlbaum.

Stevenson, H. W., Parker, T., Wilkinson, A., Bonnevaux, B., \& Gonzales, M. (1978). Schooling, environment, and cognitive development: A cross-cultural study. Monographs of the society for research in child development, 43(3, Serial No. 175).

Stevenson, H. W., \& Weir, M. W. (1963). The role of age and verbalization in probabilitylearning. American Journal of Psychology, 76, 299-305.

Strauss, S., \& Stavy, R. (Eds.) (1982). U-shaped behavioral growth. New York: Academic Press.

Weir, M. W. (1964). Developmental changes in problem-solving strategies. Psychological Review, 71, 473-490.

White, S. (1965). Evidence of a hierarchical arrangement of learning processes. In L. P. 
Lipsitt \& C. C. Spikers (Eds.), Advances in child development and behavior (Vol. 2, pp. 187-220). New York: Academic Press.

Wilkinson, A., Parker, T., \& Stevenson, H. W. (1979). Influence of school and environment on selective memory. Child Development, 50, 890-893.

Willis, S. (1987). Cognitive training and everyday competence. In K. W. Schaie \& C. Eisdorfer (Eds.), Annual review of gerontology and geriatrics (Vol. 7, pp. 187-220). New York: Springer.

Yates, F. A. (1966). The art of memory. Harmondsworth, England: Penguin.

RECEIVED: February 10, 1988; REVISED: August 8, 1988 